Ingenium. Revista Electrónica de Pensamiento Moderno y Metodología en Historia de la Ideas ISSN: 1989-3663

http://dx.doi.org/10.5209/INGE.62418

\title{
Modernidad, historia y lenguaje. Actualidad del pensamiento ilustrado
}

\author{
Miguel Á. Perdomo Batista ${ }^{1}$
}

Recibido: 7 de junio de 2018 / Aceptado: 8 de octubre de 2018

Resumen. En este trabajo indago sobre la actualidad de la Ilustración en relación con la modernidad, la idea de historia y el lenguaje. Examino la construcción historiográfica de la Ilustración para distinguir los tópicos que caracterizan las rupturas y las continuidades en las sucesivas interpretaciones. Posteriormente, analizo la cuestión en el contexto del debate entre modernidad y posmodernidad. Finalmente, formulo la pregunta sobre la Ilustración en relación con las posibilidades de la filosofía de la historia y con el lenguaje. Se concluye la necesidad de recuperar la filosofía de la historia como legado de la Ilustración, y se plantea cómo podría efectuarse tal recuperación.

Palabras clave: Ilustración; Filosofía de la Historia; Modernidad; Posmodernidad.

\section{[en] Modernity, history and language. Actuality of the enlightenment thought}

\begin{abstract}
This work is an exploration of the concept of Enlightenment. First, the historiographical construction of the Enlightenment is examined to distinguish topics that characterized the ruptures and continuities in the sucessive interpretations. Subsequently, the issue is discussed in the context of the debate between Modernity and Postmodernity. Finally, question about the Enlightenment is discussed in relation to the possibilities of the philosophy of history and language. It concludes the need to recover the philosophy of history as legacy of the Enlightenment, and considers how such a recovery could be made.
\end{abstract}

Key words: Enlightenment, Philosophy of History, Modernity, Posmodernity.

Cómo citar: Perdomo, M. (2018). Modernidad, historia y lenguaje. Actualidad del pensamiento ilustrado, en Ingenium. Revista Electrónica de Pensamiento Moderno y Metodología en Historia de la Ideas $12,35-50$.

En un trabajo reciente, Asunción Herrera afirmaba el valor de la Filosofía y la Literatura como instrumentos para recuperar una nueva Ilustración cuyos contenidos emancipatorios sirvan de alternativa al mundo de la globalización ${ }^{2}$. Pero el problema es precisamente determinar qué es o qué fue exactamente la Ilustración. Pues en efecto, puede decirse que pocas etapas históricas habrán suscitado tantas polémicas y porfías como la Ilustración. Hasta el punto de que todavía no estamos muy seguros

1 miguel.perdomo@ulpgc.es

2 A. Herrera Guevara, "Filosofía y literatura: dos herramientas necesarias ante los retos de una nueva Ilustración", Araucaria, 19 / 38 (2017), 25-47. DOI: 10.12795/araucaria.2017.i38.02. 
de saber bien lo que es. Se trata de una cuestión recurrente que surge a finales del siglo XVIII, atraviesa las dos últimas centurias, y llega hasta nosotros en un estado que no augura una solución inmediata. La pregunta sobre la Ilustración tiene actualidad porque, como señala Padgen ${ }^{3}$, algunos de los términos más importantes en la discusión sobre el significado de "humanidad" -como modernidad, posmodernidad, universalismo, imperialismo o multiculturalismo- remiten a determinada interpretación de la Ilustración. Se trata de saber, además, hasta qué punto los valores ilustrados rigen nuestro mundo.

En realidad, la "cuestión" de la Ilustración no comprende un solo debate, sino varios, y esta es una de las principales dificultades para alcanzar respuestas satisfactorias. En efecto, se puede entender el movimiento ilustrado como una etapa histórica, como un movimiento político, social o cultural, como una forma de pensamiento, un proceso intelectual permanente o una actitud o como varias de estas cosas a la vez. De modo que el debate sobre la Ilustración es doble: intelectual y sociopolítico. Una u otra consideración modifican el sentido y los resultados de la discusión, y han ido configurando un concepto del movimiento ilustrado que naturalmente también tiene su historia, como muestra el trabajo de Roche y Ferrone ${ }^{4}$. Es preciso tener en cuenta esa historia para descubrir rupturas y continuidades, pero también para advertir las interpretaciones erróneas.

Otra de las dificultades es saber si el movimiento ilustrado significó lo mismo en todas partes, es decir, si debemos hablar de "Ilustración" o más bien de "Ilustraciones". Las diferentes denominaciones que el movimiento adoptó en cada país -"Aufklärung, Enlightenment, Lumières, Illuminismo"- parecen avalar esta interpretación, que se generalizó en las últimas décadas del siglo XX a partir de las investigaciones inspiradas por la historia cultural de la Ilustración. En efecto, como señalan Roche y Ferrone ${ }^{5}$, la consideración del movimiento ilustrado como un fenómeno esencialmente cultural antes que social o político plantea la necesidad de prescindir de toda definición homogénea y unitaria en beneficio de una diversidad que podría explicarse en los siguientes términos.

En primer lugar, señalan, se debe tener en cuenta que el movimiento ilustrado se desarrolló a partir de la alternancia de sucesivos momentos de ruptura y retroceso. En segundo lugar, y como consecuencia de lo anterior, la Ilustración se manifestó de forma diversa en el tiempo y en el espacio. En tercer lugar, la Ilustración no se presenta como un cuerpo doctrinal sistemático cuyos principios son aplicables en todo momento, sino más bien como un conjunto de valores a partir de los cuales se va articulando un espacio público cuyo elemento nuclear es la actitud crítica. Finalmente, existían diferentes tradiciones nacionales de acceso a la cultura, y las relaciones de la cultura con el poder y con la Iglesia no fueron las mismas en todas partes.

Según ellos, la unidad del movimiento ilustrado viene dada por la crítica generalizada a la sociedad del Antiguo Régimen, y las diferencias se deben a la mayor o menor radicalización de esa crítica. La Ilustración europea fue una "construcción sin límites" que se universalizó a partir de la síntesis francesa. En el caso de España

\footnotetext{
A. Padgen, “¿Qué es la Ilustración?”, Eunomía. Revista en Cultura de la Legalidad, 8 (2015), 3-14.

D. Roche, y V. Ferrone, "Historia e historiografía de la Ilustración". En D. ROCHE, y v. FERRONE, (Eds.). Diccionario histórico de la Ilustración, Madrid, Alianza Editorial, 1988, 415-480.

D. Roche, y V. Ferrone, Diccionario histórico de la Ilustración, 459-475.
} 
y Portugal, plantean ${ }^{6}$ una Ilustración orientada por literatos y administradores hacia una "regeneración utilitarista" condicionada por la coyuntura política y el apoyo de los gobiernos?.

No obstante, es necesario precisar que el plural del propio término "Ilustraciones" remite a un significado común, y que se le está reclamando a la Ilustración lo que no cabe exigir a ningún acontecimiento histórico, que es diverso siempre en sus determinaciones concretas. Debe advertirse también que no debe confundirse uniformidad con unidad, y que la negación del carácter general del movimiento termina siendo ella misma una forma de definición, una generalización. Por lo demás, es preciso señalar que la historia cultural es una respuesta a la crisis que vive la historiografía desde finales del siglo pasado, sobre todo a partir de la superación de la idea ilustrada de la historia como progreso y, consecuentemente, de la quiebra de los principios de objetividad y universalidad, pues se considera que la verdad es la expresión de unas prácticas sociales concretas, y la realidad se convierte en un discurso relacionado con tales prácticas. Esta disolución del pensamiento histórico clásico tuvo lugar en el contexto del debate entre modernidad y posmodernidad, cuestión a la que volveremos a referirnos más adelante.

La discusión sobre la naturaleza y la actualidad del movimiento ilustrado y sobre sus consecuencias enfrenta a detractores, críticos y valedores de la Ilustración. Entre los primeros se hallan, por ejemplo, los partidarios del nacionalismo excluyente y los fundamentalistas de uno u otro signo. Entre los críticos se encuentran quienes denuncian el carácter imperialista que oculta la globalización y cuestionan el etnocentrismo occidental. Para John $\mathrm{Gray}^{8}$, aunque la Ilustración proponía la "emancipación universal", en realidad no era sino otra forma del imperialismo cultural de Occidente. Señala que los modernos son herederos poscoloniales de la Ilustración, y que ya no gobiernan en nombre de la civilización y la emancipación, sino en nombre del "desarrollo, la democracia, la buena gobernanza y el estado de derecho", y que sus agentes ya no son los estados nacionales, sino el FMI, el Banco Mundial y otras agencias de ayuda internacional cuyos propósitos son bienintencionados pero ingenuos. El origen de esta situación habría sido la "tiranía" de la razón impuesta por la Ilustración, que suponía que todos los pueblos debían determinar su forma de vida únicamente a partir de un criterio de racionalidad universal, independientemente de sus tradiciones, costumbres y creencias.

Estas críticas tienen como precedente la obra de Adorno y Horkheimer, que reclamaban el proyecto incumplido de la Ilustración:

La aporía ante la que nos encontramos en nuestro trabajo se reveló así como el primer objeto que debíamos analizar: la autodestrucción de la Ilustración. No albergamos ninguna duda -y esta es nuestra petitio principii-de que la libertad en la sociedad es inseparable del pensamiento ilustrado. Pero creemos haber descubier-

D. Roche, y V. Ferrone, Diccionario histórico de la Ilustración, 473.

En el caso de España, y a propósito de la ascensión social y política de los Iriarte, Autor (2011: 196-197) ha señalado, por ejemplo, que fueron los funcionarios y los servidores reales quienes permitieron acometer las reformas y quienes en definitiva sostuvieron al movimiento ilustrado, y que este podría ser interpretado como la instrumentalización de la crítica histórica surgida a fines de la centuria anterior, puesta ahora al servicio del absolutismo borbónico.

8 J. Gray, Enlightenment's Wake Politics and Culture at the Close of the Modern Age, Londres y Nueva York, Routledge, 1997. 
to con igual claridad que el concepto de este mismo pensamiento, no menos que las formas históricas y concretas y las instituciones sociales en que se halla inmerso, constituyen ya el germen de aquella regresión que hoy se verifica por doquier. Si la Ilustración no asume en sí misma la reflexión sobre este momento regresivo, firma su propia condena. En la medida en que deja a sus enemigos la reflexión sobre el momento destructivo del progreso, el pensamiento ciegamente pragmatizado pierde su carácter superador, y por tanto también su relación con al verdad. ${ }^{9}$

Y en efecto, según Roche y Ferrone ${ }^{10}$, Adorno y Horkheimer habían tomado de Cassirer ${ }^{11}$ su idea -por otra parte cuestionable- de que la Ilustración identificaba la verdad con el conocimiento científico, y de ella deducían la inevitable transformación de la Ilustración en positivismo. El discurso emancipatorio ocultaba una voluntad de dominio y poder, pues quien controla la naturaleza acaba controlando también a la sociedad bajo el pretexto de su racionalización, y de ahí la esencial vinculación entre ciencia, tecnología y totalitarismo. El origen de la alienación es la reducción de toda racionalidad a la racionalidad tecnológico-instrumental. La tecnología, convertida ya en un fin en sí mismo, encarna el único criterio de racionalidad, de modo que lo racional es adaptar los medios a los fines, y el progreso racional equivale al progreso técnico:

Cuanto más complicado y sutil es el aparato social, económico y cintífico, a cuyo manejo el sistema de producción ha adaptado desde hace tiempo el cuerpo, tanto más pobres son las experiencias de las que este es capaz. La eliminación de las cualidades, su conversión en funciones, pasa de la ciencia, a través de la racionalización de las formas de trabajo, al mundo de la experiencia de los pueblos y asimila tendencialmente a este de nuevo al de los batracios. La regresión de las masas consiste hoy en la incapacidad de poder oír con los propios oídos aquello que no ha sido aún oído, de tocar con las propis manos aquello que no ha sido aún tocado: la nueva figura de ceguera que sustituye toda ceguera mítica vencida. A través de la mediación de la sociedad total que invade todas las relaciones y todos los impulsos, los hombres son reducidos de nuevo a aquello contra lo cual se había vuelto la ley de desarrollo de la sociedad, el principio del sí mismo: a simples seres genéricos, iguales entre sí por aislamiento en la colectividad coactivamente dirigida ${ }^{12}$.

Debemos señalar, no obstante, que, en general, los filósofos de la escuela de Frankfurt se adhieren claramente a los ideales instaurados por la Ilustración. La crítica a las sociedades del capitalismo avanzado persigue convertir en realidad los ideales ilustrados, y, por ello, los intereses que presidan la actividad filosófica deben tener un carácter emancipatorio. Se trata, por decirlo así, de una crítica ilustrada de la Ilustración, pues, en definitiva, la crítica a la Ilustración de Adorno y Horkheimer está en la base de una utopía formulada en términos negativos como negación del estado de cosas presente, única garantía de que la utopía no pueda ser instrumentalizada y devenir en una nueva tentación totalitaria.

Adorno y Horkheimer, Dialéctica de la Ilustración, Barcelona, Círculo de Lectores, 1999 [1947], 43-44.

D. Roche, y V. Ferrone, Diccionario histórico de la Ilustración, 449.

E. Cassirer, Filosofía de la Ilustración, México, FCE, 1972 [1943].

Adorno y Horkheimer, op. cit., 86. 
Finalmente, entre los defensores de la Ilustración cabe citar a quienes reivindican su aportación a los valores esenciales de nuestro tiempo. Padgen ${ }^{13}$, por ejemplo, señala la fe en la razón, el laicismo, la tolerancia, los derechos humanos o el valor de la investigación científica:

Si nos consideramos modernos, progresistas, tolerantes y, en general, de mentalidad abierta, si no nos asusta la investigación de las células madre y sí las creencias religiosas fundamentalistas, tendemos a considerarnos ilustrados.

$[\ldots]$

A la Ilustración se debe también el concepto moderno de sociedad global. [...] Al observador un poco escéptico le parecerá un objetivo lejano lo que en cierta ocasión se llamó optimistamente en las Naciones Unidas «Nuestra Comunidad Global».

$[\ldots]$

La mayor parte de lo conseguido desde el final de la Segunda Guerra Mundial hasta hoy se debe a su herencia [de la Ilustración]. En un mundo lleno de regímenes corruptos, homicidas y en nada ilustrados puede parecer un logro muy modesto. Pero frente a ese comportamiento no ilustrado, sobre todo en el ámbito internacional, la mayoría de los estados más poderosos, aunque solo sea en apariencia, aceptan la universalidad de los derechos humanos y de la justicia, que no son-como proclamó en una ocasión el Ayatolá Jomeini- una mera expresión cultural del imperialismo de Occidente. Contamos con un Tribunal Internacional de Justicia de 1998, y con un Tribunal penal Internacional [...] Pese las acusaciones de ser poco más que agentes de un nuevo tipo de «imperio no oficial», el Banco Mundial y el Fondo Monetario Internacional [...] tratan de lograr que todas las naciones alcancen los niveles económicos medios, y por eso mismo sociales, característicos de los estados del mundo «desarrollado». Puede que ciertos aspectos como «comunidad internacional» $\mathrm{o}$ «gobernación global», carezcan de contenido específico; pero el simple hecho de que se utilicen estas expresiones e impongan un cierto respeto puede constituir un motivo de esperanza.

Giddens ${ }^{14}$ considera que los valores de la Ilustración no han desaparecido, porque son la base para la legislación internacional, la economía de mercado o la globalización de ciertas instituciones modernas como la democracia, y por lo tanto no puede hablarse de un desplazamiento de la modernidad por la posmodernidad. Por su parte, y a diferencia de la utopía negativa de Adorno y Horkheimer, Habermas da un contenido positivo a la utopía ilustrada desarrollando un nuevo concepto de racionalidad, la racionalidad comunicativa, a la que volveremos a referirnos.

La aportación de Padgen ${ }^{15}$ me interesa especialmente, porque atribuye las críticas a la "tiranía" de la razón ilustrada a una interpretación errónea de la Ilustración. En efecto, y según se advierte en Condorcet o en Kant, el pensamiento ilustrado no excluía el conocimiento de las pasiones, porque lo que definía a la humanidad era la

13 A. Padgen, La Ilustración y por qué sigue siendo importante para nosotros, Madrid, Alianza Editorial, 2015, 21-29.

14 A. Giddens, "Estamos en un proceso de reconstrucción del estado nacional, entrevista realizada por José Manuel Costa", $A B C$, (02-05-2000), 47-49. Puede consultarse en línea en le Hemeroteca digital de $A B C$ : http://hemeroteca.abc.es/ [consultado el 1 de octubre de 2017].

15 A. Padgen, “¿Qué es la Ilustración?”, Eunomía, 8 (2015), 3-16 
empatía, que permitía reconocer el valor de todos los seres humanos y la posibilidad del bien común. Según Padgen, lo que caracterizaba al movimiento ilustrado era el intento de redefinir la naturaleza humana. Se afirmaba la existencia de una "naturaleza humana universal", y esta era el fundamento de la creencia en un "destino humano universal", una vida política y social compartida.

Como podrá advertirse, en el planteamiento de Padgen la Ilustración aparece formulada en los términos de una filosofía de la historia. Y me parece significativo porque creo que la actualidad de la Ilustración reside no solo en las soluciones que propuso y sus consecuencias históricas, sino también, y acaso sea esto lo más importante, en la cuestión que plantea y nos obliga a preguntarnos por ella en nuestro presente, que es aquello que no se ha cancelado. Quizá por eso insistía Foucault ${ }^{16}$ en la necesidad de evitar lo que denominaba el "«chantaje» de la Aufklärung", es decir, su planteamiento polémico, según el cual hay que estar a favor o en contra de la Ilustración.

Foucault ${ }^{17}$ señaló que en la definición kantiana de la "Aufklärung", la crítica era el instrumento necesario para evitar que razón cayera bajo la tutela ajena. A partir de aquí la crítica había adoptado el aspecto de una desconfianza hacia la razón, y la reflexión sobre el presente quedó oscurecida por la cuestión sobre la verdad de nuestros conocimientos, de modo que la ontología del presente pasó a depender de la ontología de la verdad. Así pues, insistía Foucault, Kant se halla en el inicio de las dos tradiciones críticas que recorrían la modernidad. Una es la analítica de la verdad u ontología formal de la verdad, que examina las condiciones que hacen posible un conocimiento verdadero. La otra es la que pregunta por la actualidad, por lo que somos en nuestro presente ("Was ist Aufklärung?": ¿Qué es la Ilustración?), y es una ontología del presente, una reflexión histórica sobre nosotros mismos, sobre el poder y sobre la forma en que somos gobernados.

Foucault ${ }^{18}$ añadió posteriormente que la cuestión que "aparece por primera vez en este texto de Kant es la cuestión del presente, la cuestión de la actualidad: ¿qué es lo que pasa hoy día? ¿Qué es lo que pasa ahora? ¿Y qué es este «ahora» en cuyo interior nos encontramos unos y otros, y que define el momento en que escribo?". En el texto de Kant, la filosofía se planteaba como "problematización de la actualidad", una interrogación del filósofo sobre aquella misma "actualidad" de la cual forma parte. Tal actitud, afirmaba Foucault, es la que caracteriza a la filosofía como discurso de la modernidad. La "Aufklärung" fue la primera época que se dio nombre a sí misma. Y no lo hizo en función de una idea tradicional sobre la alternancia entre apogeo y decadencia, sino como un acontecimiento dentro de la historia general del pensamiento dentro de la cual ella misma desempeñaba un papel. Foucault ${ }^{19}$ se planteó después si no podría definirse la modernidad más como una actitud que como un período de la historia. Tal actitud podría caracterizarse como una interrogación sobre nuestra relación con el presente, es decir, "como una crítica permanente de nuestro ser histórico".

Como se habrá advertido, las ideas del pensador francés tienen como referencia la cuestión de la historia en el contexto de la reflexión sobre modernidad, y en tal

\footnotetext{
M. Foucault, Sobre la Ilustración. Michel Foucault. Madrid, Tecnos, 2006, 87.

Ibid., 24 y ss.

Íbid., 54-55.

Ibid., 81 y 86.
} 
sentido, la pregunta por la Ilustración remite forzosamente a la discusión sobre la modernidad y la posmodernidad.

En efecto, a partir de la década de los setenta y los ochenta del siglo pasado asistimos al debate entre quienes consideran que la modernidad (y por tanto el programa ilustrado) ha sido rebasada por la posmodernidad, y quienes creen que el proyecto ilustrado de la modernidad no ha perdido su vigencia, y que es necesario retomarlo una vez corregidos sus errores. Lo primero ha sido defendido, entre otros, por Gianni Vattimo y Jean-François Lyotard; lo segundo, como ya se ha señalado, por los pensadores de la Escuela de Frankfurt, y singularmente por Jürgen Habermas.

Gianni Vattimo sitúa los antecedentes del "posmodernismo" en la "actitud" de rechazo adoptada por Nietzsche y Heidegger ante una modernidad entendida en los términos de una idea de la historia basada en la superación, es decir, en el progreso. Según Vattimo ${ }^{20}$, ambos pensadores consideraban que la modernidad podía caracterizarse como un proceso dominado por la idea de un apropiación cada vez más plena de los "fundamentos", de los "orígenes", de suerte que las revoluciones se presentan y se legitiman como "recuperaciones, renacimientos, retornos". La idea de "superación" concibe el curso del pensamiento como un desarrollo progresivo en el cual lo valioso se identifica con lo nuevo.

Nietzsche y Heidegger se habrían abstenido de proponer una superación crítica de tal planteamiento, pues ello habría colocado a lo posmoderno en la misma línea de lo moderno, dominada por las categorías de lo nuevo y la superación. Y, en efecto, esta es una de las objeciones más corrientes a la idea de posmodernidad. Por eso, añade Vattimo ${ }^{21}$, lo posmoderno no se caracteriza solo como una novedad respecto de lo moderno, sino como la misma "disolución de la categoría de lo nuevo", como una experiencia del "fin de la historia" y no como un estadio diferente de la historia misma.

Así pues, el concepto de historia se halla en una situación comprometida en la cultura contemporánea, que carece de una filosofía de la historia, lo que puede advertirse en una disolución de la historia en la práctica y la conciencia metodológica de la historiografía. Disolución que no significa "puro fin de la historia", sino ruptura de la unidad, pues el hombre de nuestro tiempo se ha dado cuenta de que la historia de un acontecimiento "es solo una historia entre otras", una historia que tiene también carácter ideológico, y que, además, y por si esto fuera poco, desde el punto de vista textual no es más que un relato, una narración ${ }^{22}$.

Ahora bien, Vattimo ${ }^{23}$ plantea la condición posmoderna en términos positivos aludiendo a sus posibilidades constructivas. Tales posibilidades requieren que nos coloquemos en la posición de un "debilitamiento del ser". Esto significa que debemos concebir la verdad no en los términos fuertes de una metafísica que la interprete partiendo del modelo positivo del conocimiento científico, sino en los términos más generales de la verdad entendida, por ejemplo, como una experiencia estética o retórica. Todo lo cual nos lleva a la necesidad de un "pensamiento débil", para el que la realidad se aligera porque está menos claramente dividida entre lo verdadero y lo

20 G. Vattimo, El fin de la modernidad. Nihilismo y hermenéutica en la cultura posmoderna, Barcelona, Gedisa, 1995 (1986), 10.

Ibid., 12-15.

Ibid., 16-17.

Ibid., 18-20. 
ficticio. Nos movemos en un horizonte de incertidumbre, pues la certeza de un hecho es relativa en tanto que depende de una interpretación. Según Vattimo, todo ello encierra una oportunidad, porque abre el camino hacia la tolerancia y la pluralidad. No obstante, y aunque así fuera, tendríamos que preguntar de qué modo podríamos eludir el relativismo o la instrumentalización a que puede conducir la ausencia de un marco de referencias claro.

Por su parte, Jean-François Lyotard ${ }^{24}$ afirma que en las sociedades premodernas la función legitimadora - es decir, la tarea de proporcionar unidad a la sociedad y la cultura- la proporcionaban los discursos míticos y religiosos. Pero esto habría cambiado radicalmente con la llegada de la modernidad, a partir de la cual la legitimación se basa en una determinada idea de razón, un metarrelato cuya función legitimadora se desarrolla en el ámbito científico y cultural. Los metarrelatos que corresponden a la modernidad son los de la dialéctica del espíritu, la hermenéutica del sentido y la emancipación del sujeto razonante o trabajador. Para Lyotard, hoy resultaría imposible legitimar el progreso apelando a la emancipación de la humanidad, pues constatamos que el desarrollo tecnológico posee su propio ritmo, totalmente independiente de las necesidades de los hombres:

En la sociedad y la cultura contemporáneas, sociedad postindustrial, cultura post moderna, la cuestión de la legitimación del saber se plantea en otros términos. El gran relato ha perdido su credibilidad, sea cual sea el modo de unificación que se le haya asignado: relato especulativo, relato de emancipación.

Se puede ver en esa decadencia de los relatos un efecto del auge de las técnicas y tecnologías a partir de la Segunda Guerra Mundial, que ha puesto el acento sobre los medios de la acción más que sobre los fines, o bien el del redespliegue del capitalismo liberal avanzado tras su repliegue bajo la protección del keynesianismo durante los años 1930-1960, auge que ha eliminado la alternativa comunista y que ha revalorizado el disfrute individual de bines y servicios ${ }^{25}$.

Esta imposibilidad de aceptar los metarrelatos de la modernidad es lo que caracteriza la posmodernidad, y debemos enfrentarnos a la desaparición de la idea de progreso como argumento fundamental de la historia humana, tal y como había quedado establecido a partir de la Ilustración. En tanto que proyectado hacia un fin, el tiempo histórico se concebía entonces como algo continuo, irreversible y universal, y el progreso era el referente absoluto del sentido de todo lo acontecido en el pasado. Con la llegada de la posmodernidad, se duda de tales presupuestos, y se pone de manifiesto la inviabilidad de un proyecto histórico basado en los postulados ilustrados. Lyotard señala que la posmodernidad niega la existencia de reglas de conocimiento para hablar en su lugar de negociación y de procesos sociales, es decir, de la verdad como consenso. Pero cabe preguntarse si la negativa de Lyotard no termina convirtiéndose también en un metarrelato, una metanarrativa absoluta: la negación de todo metarrelato.

Habermas ha sido uno de los principales críticos de la posmodernidad, que para él en realidad es una antimodernidad. Define a los posmodernos como "neoconservadores", pues al rechazar las metanarraciones están rechazando también la posibilidad

J.-F. Lyotard, La condición postmoderna: Informe sobre el saber, Madrid, Cátedra, 1984.

25 Ibid., 73. 
de una legitimación de carácter universal sobre el que sustentar la crítica misma. La posibilidad de crítica está sujeta a la existencia de una teoría que delimite y haga explícitos los términos y el sentido de la discusión. Sin teoría, la crítica abandona el ámbito de la racionalidad y deviene ideología, crítica "ad hoc", como señala, por ejemplo, a propósito del criticismo de Adorno y Horkheimer. Así pues, abandonar el criticismo racional tal y como fue concebido por los ilustrados es abandonar la racionalidad misma, porque al carecer de un estándar es imposible distinguir entre lo descubierto y lo enmascarado. Sin un consenso sobre la verdad, la crítica se convierte en mero criticismo coyuntural dependiente del contexto, traicionando a la racionalidad moderna.

Para Habermas resultan irrenunciables ciertos valores democráticos de igualdad y ciudadanía aun reconociendo los fallos de la modernidad y de su centro ilustrado, pues tales valores son la única salvaguarda frente a la fragmentación social. Por tanto, en lugar de proponer una posmodernidad, es necesaria una nueva Ilustración de la modernidad que corrija sus errores pero preserve los logros de ciudadanía y democracia. Defiende una convivencia plural bajo el primado de los derechos humanos como base normativa orientada hacia una vida libre de la dominación. En definitiva, se trata de imponer un verdadero interés emancipador frente al interés práctico e instrumental de la racionalidad del capitalismo tardío. Para Lyotard, sin embargo, las ideas de Habermas no son sino un metarrelato más: la "metanarrativa de la emancipación"'26.

Por otra parte, el principio del consenso como criterio de validaciópn parece también insuficiente. O bien es el recuerdo de los hombres en atnto que inteligencias cognoscentes y voluntades libres obtendio por medio del diálogo. Es en esta forma como se encuentra elaborado por Habermas. Pero esta concepción reposa sobre la validez del relato de la emancipación ${ }^{27}$.

El debate sobre la modernidad y la posmodernidad se ha ido transformando en los últimos años. El propio término "posmodernidad" ha perdido presencia en el análisis de la realidad a favor de otras categorías como "modernidad tardía, globalización o capitalismo tardío"28. Ulrich Beck ha venido desarrollado desde mediados de los ochenta el concepto de "sociedad del riesgo", y más recientemente el de "sociedad del riesgo global". Por su parte, Zygmunt Bauman habla de una "modernidad líquida" contrapuesta a la "modernidad sólida" 29 .

26 Cito por R. Rorty, "Habermas y Lyotard sobre la posmodernidad”, en R. J. Berstein, (Ed.), Habermas y la modernidad, Madrid, Cátedra, 1988, 254-256

27 Lyotard, Jean-François, La condición posmoderna, Madrid, Cátedra, 1984, 109.

28 R. Rodríguez, "Transmodernidad: un nuevo paradigma", en Orbis Tertius, 1 (2007), 98, ha propuesto el concepto de transmodernidad, definida como el primado de lo virtual en un mundo caracterizado por la simulación, la hiperrealidad y la globalización. Se trata de un nuevo paradigma, un nuevo metarrelato que no surge de un propósito emancipador como en la modernidad, sino del "efecto inesperado de la comunicación, la nueva dimensión del mercado y de la geopolítica. Globalización económica, política, informática, social, cultural, ecológica... donde todo está interconectado, configurando un nuevo magma fluctuante, difuso, pero inexpugnablemente totalizador".

29 J. F. Durán afirma lo siguiente: "para Bauman ya no cabe hablar de una sino de dos modernidades [...] cada una de esas modernidades, la solida y la líquida, estaría atravesada por una temporalidad que estructura y legitima el orden social de esos dos momentos históricos". La primera, definida por la producción y el trabajo, poseía instituciones estables y sólidas (el estado, la fábrica, la escuela). La segunda, definida por el consumo, 
Para $\mathrm{Beck}^{30}$, la mayor parte de los desafíos a los que se enfrentan los seres humanos en su vida social ya no provienen de la naturaleza, sino de las consecuencias de las propias acciones humanas. La sociedad del riesgo es un segundo tipo de sociedad moderna, posterior a la sociedad industrial y con distintas orientaciones normativas. $\mathrm{Si}$ en la primera se establece como primera demanda la igualdad, en la segunda la exigencia principal es la seguridad. Según él ${ }^{31}$, el concepto de riesgo modifica la relación entre el pasado, el presente y el futuro, pues el pasado ha perdido su poder para determinar el presente y ha sido sustituido por el futuro como causa de las experiencias. Si antes el futuro era el lugar en el que se cumplirían las potencialidades del presente, ahora adquiere el valor de referencia crítica para las acciones sociales. En la sociedad de la globalización, el riesgo tiene que ver con una evaluación continua de las innovaciones tecnológicas desde el punto de vista de la seguridad, y no con el respeto a los derechos humanos, como sucede en las sociedades aún marcadas por los objetivos de la modernidad. Pero ello no supone que deba renunciarse a un examen crítico de la realidad: hay "una utopía en la sociedad del riego y en la teoría de la sociedad del riego, la utopía de una modernidad "«responsable», la utopía de «otra» modernidad" 32 .

Por su parte, Bauman ${ }^{33}$ afirma que la sociedad de comienzos del siglo XXI no es menos moderna que la del XX, y a lo sumo podría decirse "que es moderna de manera diferente". El concepto de "modernidad líquida" quiere expresar esa novedad: se trata de una disolución de "los vínculos entre las elecciones individuales y las acciones colectivas", entre la vida individual y la política. La metáfora se comprenderá si se tiene en cuenta que "los fluidos no conservan una forma durante mucho tiempo, y están constantemente dispuestos (y proclives) a cambiarla"; por eso asociamos la "fluidez" con la movilidad y la inconstancia. Actualmente, las pautas y configuraciones ya no están determinadas ni resultan evidentes, y en vez de orientar nuestra vida deben derivar de ella, son una tarea individual y no un poder coercitivo.

Según Bauman, en esta nueva modernidad, el hombre ha adquirido conciencia de los dolorosos límites de la modernidad. Pero a pesar de esta desilusión, el reto de la emancipación sigue vigente, aunque haya dejado de ser un problema social e histórico para convertirse en una cuestión individual y contingente. La tarea de la modernidad ha sido volcada sobre la autoafirmación del individuo, que ya no reclama una sociedad más justa y humana, sino su derecho a ser diferente y a elegir la forma de vida y el modelo de felicidad que le parezcan más convenientes. Las tareas y responsabilidades de la modernización se han privatizado. La consecuencia de todo esto es que lo privado "ha colonizado" lo público, cuyo espacio se ha reducido cada vez más. La mayor contradicción radica en que, al adelgazar el espacio público, el derecho a la autoafirmación está diluyendo la capacidad de controlar los mecanismos

posee instituciones menos sólidas y más transitorias, que no son capaces de dar sentido a largo plazo a la vida individual o colectiva. J. F. Durán, "Tiempos líquidos. Configuraciones de la temporalidad actual en la obra de Zygmunt Bauman", Aposta, 60 (2014), 3-4, Disponible en: www.apostadigital.com/revistav3/hemeroteca/ duran1.pdf [consultado el 1 de octubre de 2017].

30 U. Beck, «Retorno a la teoría de la sociedad del riego», Boletín de la Asociación de Geógrafos Españoles, 30 (2000), 9-20.

Ibid., 11.

Ibid., 20.

Z. Bauman, Modernidad líquida, Buenos Aires, FCE, 2003, 8, -10-12 y 33. 
sociales que la hacen viable. Por eso afirma Bauman 34: "Ahora es la esfera pública la que necesita desesperadamente ser defendida contra la invasión de lo privado -paradójicamente, para ampliar la libertad individual, y no para cercenarla-".

Para mi propósito, no son tan interesantes el resultado y las posibilidades de la discusión sobre la modernidad y la posmodernidad, como los términos mismos en que tal discusión tiene lugar. Pues, ciertamente, bien se adopte una actitud contraria a la existencia de la posmodernidad en beneficio de la modernidad, bien se afirme la superación de esta por la posmodernidad, bien se intente una síntesis integradora de ambas o se propongan otras conceptualizaciones, lo importante es que todas estas posibilidades tienen como horizonte la cuestión de la historia. Y en efecto, la historia es el horizonte de la discusión sobre la modernidad y la posmodernidad, ya sea porque se conciba la modernidad en los términos de la existencia de una historia unitaria y se proponga la recuperación de ciertos rasgos de unidad y objetividad, ya sea porque la posmodernidad se conciba justamente como la disolución de la historia. En un sentido positivo y en otro negativo, la modernidad, y con ella la Ilustración, queda definida por lo que en esencia es: una filosofía de la historia, y más exactamente, la irrupción misma de cierta filosofía de la historia y, sobre todo, su consolidación, como veremos a continuación.

Para Kant ${ }^{35}$, la Ilustración supone una toma de conciencia de las posibilidades de emancipación cuyo objetivo es alcanzar la dignidad del hombre. La dignidad humana reside en el uso constante de la razón. Pero este solo es posible mediante la autonomía de la razón, cuyo requisito es el uso libre y público de aquella en todos los terrenos.

Ilustración significa el abandono por parte del hombre de una minoría de edad cuyo responsable es él mismo. Esta minoría de edad significa la incapacidad para servirse de su entendimiento sin verse guiado por algún otro. Uno mismo es el culpable de dicha minoría de edad cuando su causa no reside en la falta de entendimiento, sino en la falta de resolución y valor para servirse del suyo pripio sin la guía de algún otro. Sapere aude!

$[\ldots]$

Sin embargo hay más posibilidades de que un público se ilustre a sí mismo; algo que casi es inevitable, con tal de que se le conceda libertad.

$[\ldots]$

Para esta ilustración tan solo se requiere libertad y, a decir verdad, la más inofensiva de cuantas pueden llamarse así: el hacer uso público de la propia razón en todos los terrenos.

$[\ldots]$

\footnotetext{
Z. Bauman, Modernidad líquida, Buenos Aires, FCE, 2003, 57.

Cito por Kant, I., Contestación a la pregunta qué es la Ilustración, Madrid, Taurus, 2015², 17-17. Como se sabe, las ideas esenciales de Kant sobre esta cuestión están recogidas en el texto ya clásico en respuesta a la pregunta ¿Qué es la Ilustración? (Was ist Aufklärung?), planteada en 1784 por la Berliner Monatsschrift. Existen, además, otras definiciones kantianas del término "Ilustración" que no añadirían nada sustancial a lo que aquí vamos a exponer. Se trata de una nota en el opúsculo titulado ¿Qué significa orientarse al pensar?, publicado en 1786, y del párrafo n. ${ }^{\circ} 40$ de la Crítica del juicio. Pueden consultarse estos textos en I. Kant, ¿Qué es la Ilustración? Y otros escritos de ética, política y filosofía de la historia. R. [RodríGuez] Aramayo (Ed.), Madrid, Alianza Editorial, 2004. Para otros textos de Kant relacionados con estas cuestiones puede consultarse R. Aramayo, "Kant y la Ilustración”, Isegoría, 25 (2001), 293-309. Puede verse también C. la Roca, “Kant y la Ilustración”, Isegoría, 35 (2006), 107-127, que examina el Opus postumum de Kant.
} 
Pues, cuando la naturaleza ha desarollado bajo tan duro tegumento ese germen que cuida con extrema ternura, a saber, la propensión y la vocación hacia el pensar libre, ello repercute sobre la mentalidad del pueblo (merced a la cual este va haciéndose cada vez más apto par al libertad de actuar) y finalmente acaba por tener un efecto retroactivo hasta sobre los principios del gobierno, el cual incluso termina por encontrar conveniente tratar al hombre, quien ahora es algo más que una máquina, conforme a su dignidad.

La exigencia de racionalidad es asumida libremente, porque solo puede ser ética si es asumida en condiciones de libertad. Por eso la imposición de la racionalidad no es en esencia un hecho totalitario, aunque hayan podido serlo sus efectos.

Entendida como una exigencia moral inmanente a la propia dignidad humana que es libremente aceptada, la Ilustración podría definirse en primer lugar como una voluntad de razón. Pero en tanto que exigencia moral, la Ilustración es un proceso, un empeño perenne cuyo futuro está condicionado a las posibilidades educativas de la República de las Letras, capaces de crear aquel espacio público que reclama el uso autónomo de la razón. Así se explica el vínculo entre Ilustración y educación. Por tanto, y en segundo lugar, cabría definir también la Ilustración como una voluntad de ilustración en el sentido pedagógico del término.

Ahora bien, como ya señaló Foucault, la pregunta de Kant sobre la Ilustración es también una pregunta de la Ilustración sobre sí misma, una crítica de la crítica que nos sitúa en el presente y abre la modernidad, pues se cuestiona el propio cuestionar, el presente del preguntar. Lo que se plantea es la actualidad discursiva del pensar en tanto que acontecimiento de un momento histórico dado. De ahí procede el carácter fundamentalmente polémico de la Ilustración, que en esencia no es consecuencia ni de los ataques de la reacción antiilustrada ni de la ideología romántica, sino que le es consustancial en tanto que teoría crítica de la historia. Al plantear la crítica de la crítica, la razón se hace histórica, pues se está planteando la pregunta de la razón como problema histórico. En este sentido, la Ilustración es una creencia en la posibilidad de que exista una teoría del presente desde la cual precisamente se puede formular la crítica. Tal teoría es la de la racionalidad de lo real. Pero al señalar el presente, la realidad se "historificó" en un antes y un después. Y en efecto, los ilustrados no solo concibieron el ideal universalista de la razón como una utopía, sino también como un criterio para reconstruir narrativamente el pasado ${ }^{36}$. Tal teoría del presente es también una escatología de la emancipación formulada paralelamente al proceso de secularización, pues, al colocar al hombre como fin y centro de un universo racional, la providencia deviene historia. La idea de progreso es justamente lo que vincula al sujeto trascendente con un mundo de contingencia, y de esta unión surge la historia, que adquiere una dimensión ontológica. Así pues, la idea de progreso es el elemento en el que confluyen racionalidad, emancipación y secularización para conformar una filosofía de la historia. Por eso, y en tercer lugar, puede definirse también la Ilustración como una voluntad de

36 Como ha señalado A. Campillo, "La invención de la Historia Universal", en A. Rivera y E. Bello (eds.), $L a$ actitud ilustrada, Valencia, Biblioteca Valenciana, 2002, 162, el ideal universalista no solo lo concibieron como una utopía o proyecto reformador para la anticipación profética del porvenir, sino también como un criterio interpretativo para la reconstrucción narrativa del pasado. El proyecto político de una humanidad unificada y reconciliada y el relato histórico de una humanidad que, inicialmente diferenciada, había ido lentamente reunificándose y reconciliándose consigo misma, constituían para los Ilustrados las dos caras de una misma empresa civilizatoria. 
historia: el apetito de futuro que el hombre siente cuando se coloca en el centro de un mundo ya secularizado y su deseo de que aquel mundo tenga un sentido. De esta forma se explica el vínculo indisoluble entre racionalidad, ética e historia, el carácter esencialmente histórico de la primera y la naturaleza axiológica de esta última ${ }^{37}$.

Desde otro punto de vista, la Ilustración tiene también los caracteres de una hermenéutica, pues supone la imposición de un sentido a la historia, es decir, su interpretación. Una historia providencialista es sustituida por otra secularizada en la que cierta idea de progreso se convierte en el sentido de la humanidad. Los ilustrados no creían que el progreso fuera inevitable, sino posible. Esta fe en el progreso se basa en la creencia de que el mundo puede llegar a tener sentido. La idea de que la relación entre virtud y felicidad puede ser algún día algo más que una mera contingencia es lo que nos salva de la condena definitiva a un interminable ciclo de iniquidades e injusticias $^{38}$. Así pues, la Ilustración también puede ser definida a partir de esa necesidad de sentido que caracteriza la modernidad. Implícitamente, Gadamer ${ }^{39}$ sitúa el pensamiento ilustrado en un horizonte hermenéutico en tanto que crítica del "prejuicio contra todo prejuicio" de la Ilustración. Pues, en efecto, si el prejuicio, como afirma Gadamer, es la base de toda comprensión, su crítica es una crítica a las deficiencias del pensamiento ilustrado en tanto que teoría hermenéutica. Pero no se trata de una hermenéutica existencial u ontológica, sino de lo que podríamos denominar, en tanto que interpretación del pasado y del presente orientada a un fin, una teleología hermenéutica. Por tanto, la Ilustración podría definirse como una teleológica hermenéutica basada en una escatología de la emancipación. Si, como afirma Gadamer ${ }^{40}$, la crítica romántica de la Ilustración desembocó ella misma en Ilustración al desarrollarse como ciencia histórica, es decir, al asimilar la comprensión racional en comprensión histórica, algo semejante podría decirse de la posmodernidad. En efecto, proponer la "disolución" de la historia no es más que extremar el historicismo, pues aquella disolución se plantea precisamente a partir de la insuficiencia de la historia, es crítica radical de la historia, es decir, una forma de filosofía de la historia. Se trata del prejuicio romántico sobre la historia, aunque se hayan invertido los términos.

Como podrá advertirse a partir de nuestro examen, la modernidad ha recobrado en los últimos años su vigencia como categoría histórica. Y con ella se han recuperado algunos de los principios fundamentales de la Ilustración, como los valores de universalidad y ciudadanía, la importancia del espacio público o el ideal emancipatorio. Y a propósito de tales contenidos emancipatorios, ha sido en el último siglo cuando se ha recordado la dimensión ética de la filosofía de la historia, como puede advertirse en la obra de Robin G. Collingwood ${ }^{41}$, para quien la historia en esencia es filosofía de la historia.

A propósito del concepto de "reactualización" propuesto por el pensador inglés, Roldán ${ }^{42}$ afirma que esta no plantea que "el historiador se ponga en el lugar del per-

\footnotetext{
Wagner se ha ocupado de las relaciones entre historia y racionalidad y de las posibilidades de una Filosofía de la Historia contemporánea que supere el relativismo cultural. Plantea la posibilidad de hallar una lógica subyacente a los diferentes criterios de racionalidad. A. Wagner, "Historia y racionalidad. Filosofía de la Historia ante los retos de pluralismo y del relativismo cultural", Azafea: Revista de Filosofia, 13 (2011), 131-150.

38 S. Neiman, “¿Qué es la ilustración?”, Revista de Occidente, 284 (2004), 66.

39 H.-G. Gadamer, Verdad y método, Salamanca, Sígueme, $1997^{7}$ (1992), vol. I, 337-353.

40 H.-G. Gadamer, Verdad y método, I, 342-343.

$41 \quad$ R. G. Collingwood, Idea de la historia, México, FCE, 2004 [1952].

42 C. Roldán, "R. G. Collingwood: el canto de cisne de la filosofía de la historia", Isegoría, 4 (1991), 165.
} 
sonaje histórico, sino más bien que la recreación de un aspecto pasado contribuya a esclarecer la situación presente del historiador". Y añade que Collingwood pretende que "los hechos históricos son en esencia filosóficos, en tanto que no importa cómo fue un suceso, sino cómo un determinado historiador piensa que fue"43. Por tanto, añadiremos nosotros, en esencia no puede haber historiografía sin su filosofía. En este contexto debe entenderse nuestra propuesta de la Ilustración como una filosofía de la historia, esto es, como la irrupción de la idea misma de la historia (cierta idea secularizada de la historia sintetizada en la noción de progreso) con sus postulados éticos (la emancipación) y epistemológicos (la razón autónoma). La identidad entre historia y filosofía de la historia propuesta por Collingwood no sería más que una consecuencia del planteamiento ilustrado, y tiene aquella misma dimensión ética, pues la recuperación del pasado es importante en la medida en que nos permite reconstruir nuestra propia identidad en un arduo proceso que no termina nunca, porque el hombre tiene que hacer su historia. La autonomía de la historia ha de sacrificarse a la autonomía del hombre (y de la razón), y la imposibilidad de una historia definitiva es el corolario de toda historicidad.

Roldán ha señalado que los ilustrados no solo le daban a la historia un valor teórico, sino también moral, pues era un instrumento al servicio de la educación y la ilustración del hombre por sí mismo. Según ella, este sería, precisamente, el legado de la filosofía de la historia ilustrada: el filósofo de la historia ya no puede anunciar lo que puede ser el futuro, pero sí puede y debe proponer "cómo debiera ser" o, en todo caso, "cómo no debiera ser jamás ${ }^{44 "}$. Así pues, lo que se plantea es que la filosofía de la historia actual tenga una dimensión ética ${ }^{45}$.

Ahora bien, esta propuesta se halla ante la dificultad de determinar los contenidos de ese "cómo no debiera ser" la historia, de manera que, de un modo recursivo, volvemos al problema de la legitimidad de los metarrelatos. Así pues, el problema no es qué relato se construye, sino "cómo" se construye y legitima esa narración, lo que nos remite a la cuestión del lenguaje ${ }^{46}$. En este contexto resultan oportunas las tempranas críticas de J. G. Hamann a la supuesta tiranía de la razón ilustrada.

Hamann fue uno de los primeros críticos de Kant, y, según Smilg47 la fuente de la que se nutrió el "Sturm und Drang", y especialmente Herder y Humboldt entre otros. Fue muy crítico con la idea ilustrada de una razón independiente y superior a

43 No obstante, C. Roldán, «¿Qué queda de la filosofía de la historia de la Ilustración?», en Manuel Cruz y Daniel Brauer (Comps.), La comprensión del pasado: escritos sobre filosofia de la historia, Barcelona, Herder, 2005 , 187-216, no está de acuerdo con la consideración de todo hecho histórico como un hecho filosófico. C. Roldán, Entre Casandra y Clio: una introducción a la Filosofía de la Historia, Madrid, Akal, 2005, ha señalado además que aún es necesario algún tipo de reflexión sobre la historia, y que, liberada de la pulsión del gran relato omnicomprensivo, la filosofía de la historia puede tener un valor ético.

44 C. Roldán, «¿Qué queda de la filosofía de la historia de la Ilustración?», en Manuel Cruz y Daniel Brauer (Comps.), La comprensión del pasado: escritos sobre filosofia de la historia, Barcelona, Herder, $2005,211$.

45 J. Rohbeck también ha expuesto la necesidad de una reorientación de la filosofía de la historia en un sentido ético, y propone su transformación en una filosofia crítica de la historia. J. Rohbeck, "Para una filosofía crítica de la historia", Isegoría, 36 (2007), 66-79.

46 Por lo demás, podría añadirse, como afirma Giddens que "la comunicación [y la transformación de sus formas y sistemas] constituye el gran hilo conductor de la historia". A. GIDDENS, "La comunicación constituye el gran hilo conductor de la historia. Entrevista realizada por Juan Manuel Costa”, $A B C$ (09-11-2003), 12-14, Puede consultarse en línea en le Hemeroteca digital de $A B C$ : http://hemeroteca.abc.es/ [Consultado el 1 de octubre de 2017].

47 N. Smilg, "Ilustración y lenguaje en el pensamiento de J. H. Hamann", en Contrastes. Revista Internacional de Filosofia, XVI (2011), 366. 
las demás capacidades erigida en guía exclusiva de la humanidad. Esta oposición era consecuencia de su concepción del lenguaje, y por eso se ha señalado que Hamann, Herder y Humboldt fueron "los protagonistas de un "giro lingüístico» primitivo"48.

Smilg ${ }^{49}$ afirma que Hamann creía que el lenguaje y el pensamiento eran lo mismo, que la razón no se podía independizar de tradiciones, creencias y experiencia, y que los ilustrados habían intentado ilusoriamente separar la razón de las condiciones históricas de su existencia, que se dan en el lenguaje. Smilg ${ }^{50}$ añade que Hamann no estaba en contra de la razón, sino en contra de la "razón monárquica", es decir, absoluta. Por eso, no debemos considerarlo como un irracionalista, sino como un "ilustrado radical”. Y añade que para Hamann no se trata de que la razón use símbolos, sino que "el pensamiento «es el uso» de símbolos, la razón «consiste» en ese ejercicio de simbolización, y por eso «el lenguaje es el único, primer y último órgano y criterio de la razón» ${ }^{51}$ ". La razón es lenguaje; no hay una facultad aislable llamada razón, y el lenguaje no es inocente, porque es nuestra forma de crear mundo.

Creo que si el lenguaje es la evidencia empírica de la historicidad de la razón, es precisamente en el lenguaje donde puede hallarse una salida al dilema de la posmodernidad. Porque si la universalidad de la razón es en realidad la universalidad del lenguaje, y si este es una manifestación de la existencia de una "naturaleza humana", como cabría deducir a partir de la tesis de Chomsky sobre la base biológica del lenguaje, la universalidad del lenguaje pone a los hombres en la tesitura de tener que hablar ${ }^{52}$.

$\mathrm{Si}$, como afirma Hamann, la palabra tiene "poder estético y lógico, porque ocupa un lugar intermedio entre los objetos de la sensibilidad y los del entendimiento", y en esta doble naturaleza reside toda posibilidad de conceptualización (Smilg 2011: 377), puede decirse, entonces, que en la palabra se dan la empatía y el concepto, y es esto los que nos permite comprender. La comprensión tiene por tanto una dimensión moral, y no solo intelectual, porque la comprensión se produce siempre históricamente, es decir, sobre el fondo de una idea de la naturaleza humana y de sus fines. El lenguaje es inseparable de la conciencia moral e histórica del hombre, y puede decirse también que, en cierto sentido, la comprensión lingüística es siempre un hecho de conciencia moral, y tiene consecuencias morales, como las tiene, también, un error de comprensión ${ }^{53}$. Lo que vincula al lenguaje con la historia es la dimensión moral de aquel, que se manifiesta históricamente y afecta a la comprensión. Reinterpretan-

\footnotetext{
N.Smilg, "Ilustración y lenguaje.., 373.

N.Smilg, "Ilustración y lenguaje.., 375.

N.Smilg, "Ilustración y lenguaje.., 377-378.

51 Sobre las dificultades para considerar a Hamann un irracionalista, puede verse también C. Canterla, "La cuestión del nihilismo en J. G. Hamann”, Pensamiento, 70, 264 (2014), 577-600. DOI: pen.v70.i264.y2014.008

52 Véanse también las ideas de La Roca sobre la razón participativa de Kant. C. la Roca, "Kant y la Ilustración", Isegoria, 35 (2006), 107-127.

53 En un nivel más práctico, y a modo de ejemplo, se podría sostener que algunos de los conflictos actuales entre Oriente y Occidente son una muestra más del continuado esfuerzo de la civilización occidental para reorganizar el mundo oriental a su propia imagen, como señala A. PADGEN, Mundos en guerra. 2500 años de conflictos entre Oriente y Occidente, Barcelona, RBA, 2011.

Sin embargo, y como argumenta Ramoneda, aunque la democracia no sea algo natural, y aunque es posible que no todo el mundo quiera la libertad, como propone Padgen (2011), no debe olvidarse la existencia de miles de ciudadanos que luchan por la libertad en sus países y esperan la complicidad de Occidente. J. Ramoneda, "Una interminable historia". El País, 15/01/2011. Como se sabe, la teoría del choque de civilizaciones fue propuesta por S. Huntington, "The Clash of Civilizations?", Foreing Affairs, 72/3 (1993), 22-49.
} 
do a Steiner ${ }^{54}$ y a Hamann, diríamos que una de las causas de la situación actual es el olvido del lenguaje, el silencio del lenguaje, ahogado ahora por la sobreinformación y por el parloteo incesante de los medios de comunicación y las redes sociales, que han convertido el silencio (y por tanto la escucha) en un bien escaso; ahogado también por una cultura de la imagen que, en el otro extremo de la racionalidad ilustrada, es la expresión de una balbuceante sentimentalidad que se expresa con el gesto.

Según Hamann ${ }^{55}$, la realidad es comunitaria, porque si un ser humano es en parte el resultado de su relación con los demás, y la narración de esas relaciones constituye su identidad, hay una historia discursiva de la humanidad en la que cada individuo puede participar interviniendo en el discurso. Este planteamiento nos obliga a dedicar unas líneas finales a las ideas de Habermas.

En efecto, Habermas ${ }^{56}$ propone un nuevo concepto de racionalidad: la racionalidad comunicativa, formulada en los términos de una pragmática universal y de una teoría consensuada de la verdad. Considera que el interés práctico y técnico debe estar al servicio del interés emancipatorio, es decir, de la promoción de la libertad y la racionalidad del hombre. Para ello es necesario desarrollar un modelo de racionalidad alternativo al de la razón tecnológico-instrumental. Como la racionalidad es universal, será necesario desarrollar una teoría sobre las condiciones universales que han de cumplirse para conseguir el entendimiento entre los hablantes. Tales condiciones han de verificarse en el lenguaje, que es donde se articula la racionalidad del hombre.

Como se habrá advertido, la universalidad de la razón en la que cree Habermas es una herencia ilustrada. Ahora bien, a diferencia de la universalidad de la razón ilustrada, Habermas considera que la universalidad de la racionalidad comunicativa no es absoluta, sino condicionada, pues depende, en definitiva, de que los hombres quieran dialogar.

54 G. Steiner, "El abandono de la palabra", en Lenguaje y silencio. Ensayos sobre la literatura, el lenguaje y lo inhumano, Barcelona, Gedisa, 2013 (1961), 29-54.

55 N. Smilg, "Ilustración y lenguaje.., 381.

56 J. Habermas, Teoría de la acción comunicativa, 2 v. Taurus, Madrid, 1987 [1981]. 